\title{
Widespread spatial and temporal extent of anthropogenic noise across the northeastern Gulf of Mexico shelf ecosystem
}

\author{
Bobbi J. Estabrook, Dimitri W. Ponirakis, Christopher W. Clark, Aaron N. Rice* \\ Bioacoustics Research Program, Cornell Lab of Ornithology, Cornell University, Ithaca, NY 14850-1999, USA
}

\begin{abstract}
The Gulf of Mexico ecosystem represents the intersection between high marine biodiversity and extensive human use and impact. Anthropogenic marine activities are prominent in the Gulf, prompting concern regarding impacts of chronic elevated noise throughout the marine ecosystem. Since sound is a critical component of the marine environment and many marine animals in the Gulf utilize sound in different aspects of their life history, their basic ecology may be negatively affected by elevated anthropogenic noise. While there are data gaps regarding the impacts of noise on marine organisms, it is crucial to understand current ambient noise conditions to evaluate the implications of noise for the Gulf ecosystem. Ambient noise measurements provide a mechanism by which to sample the cumulative acoustic activity of an ecosystem, and holistically evaluate biotic, environmental, and human-induced acoustic contributions to the overall environment. In this study, acoustic data were collected at 7 sites in the northeastern Gulf of Mexico between July 2010 and February 2012. Ambient noise is presented in 3 frequency bands (low frequency [10-500 Hz], mid-frequency [500-1000 Hz], and high frequency [1000-3150 Hz]), with median sound levels of 112, 90, and $93 \mathrm{~dB}$ (re $1 \mu \mathrm{Pa}$ ), respectively. Abiotic and anthropogenic noise sources significantly contributed to the ambient noise environment; however, seismic survey noise dominated the noise environment and chronically elevated noise levels across several paramount marine habitats. This study describes current noise conditions across the Gulf of Mexico with an intent to inform noise management strategies and investigate the potential ecological implications of elevated ambient noise.
\end{abstract}

KEY WORDS: Ambient noise - Gulf of Mexico - Anthropogenic noise · Seismic · Acoustic ecology · Acoustic monitoring

\section{INTRODUCTION}

The Gulf of Mexico fosters a variety of marine ecosystems that are rich in biodiversity. The Gulf species assemblage comprises many cetacean species (MazeFoley \& Mullin 2006), sea turtles, fishes, invertebrates, and sea birds (Love et al. 2013). Most of the organisms use sound in different aspects of their life history (e.g. foraging, reproduction, navigation, predator detection and defense) (Au \& Hastings 2008). Fifteen of the Gulf's marine species are listed as

\footnotetext{
${ }^{*}$ Corresponding author: arice@cornell.edu
}

endangered or threatened under the US Endangered Species Act (http://sero.nmfs.noaa.gov/protected_ resources/).

However, the Gulf of Mexico is also a major area of activity for oil and gas exploration and extraction, commercial fishing, and tourism; all of these activities have associated noise contributions. It is one of the most active offshore geophysical survey sites in the world (Jochens et al. 2008), and hosts 2 of the world's busiest shipping fairways and top-ranking US sea ports for container passenger vessel traffic

() The authors 2016. Open Access under Creative Commons by Attribution Licence. Use, distribution and reproduction are unrestricted. Authors and original publication must be credited. 
(www.aapa-ports.org). Since the late 1980s, anthropogenic activities in the Gulf of Mexico have increased and continue to expand into deeper waters (Jochens et al. 2008, Nixon et al. 2009), prompting concern for marine animal exposure to elevated ocean noise.

Organisms within the Gulf are continually exposed to a multitude of environmental and anthropogenic stressors, such as climate change, hurricanes, hypoxia, pollution, oil spills, shipping activity, geophysical surveys, and commercial fishing (Diaz \& Solow 1999, Day et al. 2003, Karnauskas et al. 2013). The recognition of noise pollution as a stressor for marine organisms (Southall et al. 2007, Hildebrand 2009, Slabbekoorn et al. 2010, Ellison et al. 2012) and the concerns for synergistic cumulative impacts of multiple stressors on marine ecosystems (Sih et al. 2004, Crain et al. 2008) warrant the need for evaluating noise levels and investigating the possible impacts of anthropogenic noise in the Gulf of Mexico.

In the marine environment, major contributors to ocean ambient noise include marine organisms, surface wave action, and man-made sound sources (e.g. ships, geophysical seismic surveys, underwater construction; Hildebrand 2009). These sounds are detectable over different orders of magnitude at both temporal and spatial scales, and vary in frequency content. Surface-generated environmental noise (e.g. wind, waves, and precipitation) occupies frequency ranges from approximately 0.1 to $50 \mathrm{kHz}$ (Wenz 1962, Richardson et al. 1995, Hildebrand 2009). Fish and baleen whale sounds tend to have dominant frequencies between 0.1 and $1 \mathrm{kHz}$ (Urick 1986, Richardson et al. 1995, Hildebrand 2009), but can exceed $2 \mathrm{kHz}$. Odontocetes produce sounds with most of the acoustic energy distributed in frequencies $>2 \mathrm{kHz}$ (Richardson et al. 1995). Ship noise, seismic airgun surveys, and industry operations (e.g. dredging and pile driving) typically dominate frequencies below $200 \mathrm{~Hz}$, though energy produced by those sources can exceed $1 \mathrm{kHz}$ (Richardson et al. 1995, Hildebrand 2009).

Measurements of ocean ambient noise have long been used to characterize different geographic areas from an oceanographic or physical perspective (Wenz 1962, 1972, Urick 1986) and are now being calculated in different ecosystems to evaluate how marine organisms may be influenced by sound from environmental and anthropogenic processes (Samuel et al. 2005, Simard et al. 2010, Clark et al. 2011, Merchant et al. 2015). One of the fundamental characteristics of the ambient noise environment is its variability (Wenz 1962), and, thus, long-term, large-scale sur- veys are needed to statistically characterize ambient noise spatiotemporal patterns and provide a quantitative perspective on ecosystem function. These data also offer the opportunity to evaluate whether persistent noise levels may be an additional source of stress on marine animals when aggregated with other anthropogenic disturbances. Several studies of ambient noise in the Gulf have reported statistical trends and characteristics of the acoustic environment (Newcomb et al. 2002, Snyder 2007, Snyder \& Orlin 2007); however, their data cover a limited spatial or temporal range and do not interpret the implications of current noise conditions in the context of marine animal ecology.

Here, we characterize the spectral components of the ambient noise environment in the northern Gulf of Mexico marine ecosystem over a large spatial and temporal scale to identify broad trends and major noise contributors. These data are presented to inform our knowledge concerning the potential implications of current noise conditions on local marine species and ecosystem function.

As marine anthropogenic activities increase, ocean ambient noise levels also increase (Urick 1986, McDonald et al. 2008). These elevations in anthropogenic noise can consequently interfere with conspecific communication (Southall et al. 2000, Clark et al. 2009, Williams et al. 2014), contribute to elevated stress levels (Rolland et al. 2012), and induce behavioral changes (Fewtrell \& McCauley 2012) in marine organisms. In extreme cases, high noise levels can significantly damage auditory systems (McCauley 2003), cause disorientation and stranding (Simmonds \& Lopez-Jurado 1991, Cox et al. 2006, Weilgart 2013), and even impact larval development (Aguilar de Soto et al. 2013). Currently, little is known about the influence of chronic elevated ambient noise on marine species and the ecosystem. A critical first step is to quantify long-term ambient noise patterns across the Gulf of Mexico in order to understand the magnitude of potential impacts on marine organisms within the Gulf ecosystem.

\section{MATERIALS AND METHODS}

Passive acoustic data were collected from a fixed position sensor network across the northern Gulf of Mexico along a $1135 \mathrm{~km}$ expanse of the continental shelf edge between western Louisiana and the West Florida shelf break (Fig. 1, Table 1). Acoustic recordings were made using an array of bottom-mounted Marine Autonomous Recording Units (MARUs; Ca- 


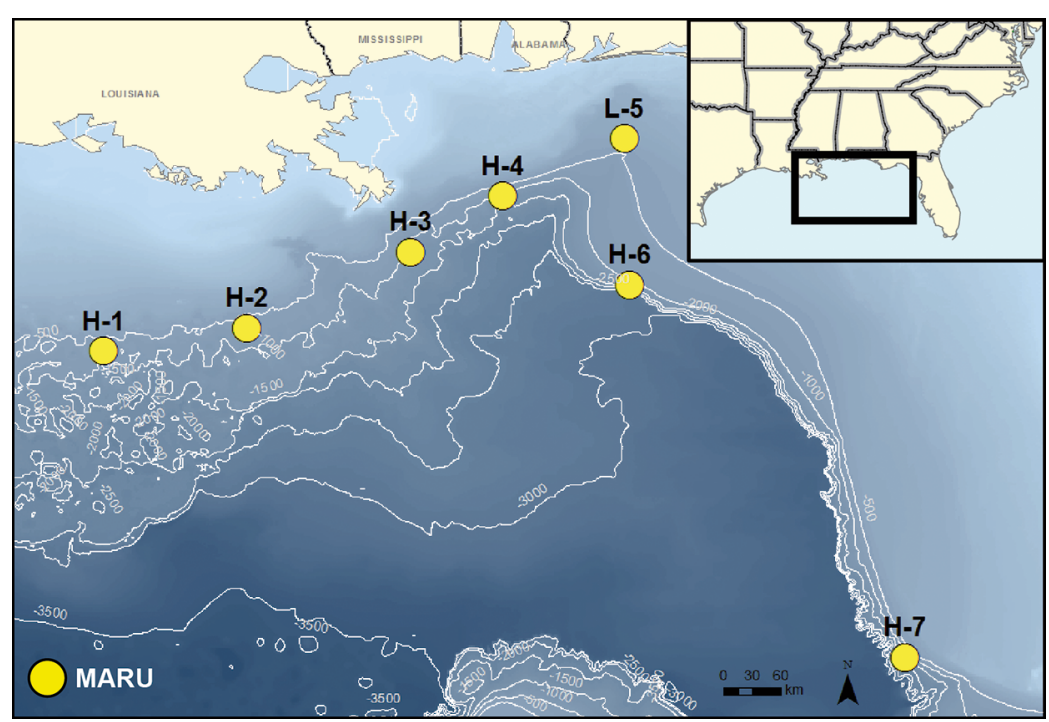

Fig. 1. High-frequency $(\mathrm{H})$ and low-frequency (L) MARU recording sites. Yellow circles: MARU recording locations; white lines: isobaths in $500 \mathrm{~m}$ intervals

lupca et al. 2000), between July 2010 and February 2012 (see Table 1). MARUs were anchored at depths ranging between 250 and $1370 \mathrm{~m}$, and recording sites were between 39 and $461 \mathrm{~km}$ apart. MARUs recorded between 3 and 6 mo in each deployment over 4 deployment periods, after which point batteries were replaced and data downloaded; the units were then re-deployed, resulting in near year-round acoustic coverage. MARUs used an HTI-94-SSQ hydrophone (High Tech; frequency response: $168 \mathrm{~dB}$ re $1 \mathrm{~V} \mathrm{\mu Pa}^{-1}$ sensitivity between 2 and $30 \mathrm{kHz}$ ), and were set to record in high-frequency $(\mathrm{H})$ or lowfrequency (L) bands as part of a broader survey effort to document the occurrence of different marine mammal species (e.g. Rice et al. 2014). The H MARUs recorded using duty-cycles with sample rates of 8 and $20 \mathrm{kHz}$ (Table 1). The 8 and $20 \mathrm{kHz}$ sample rate MARUs had lowpass filters of 3.2 and $8 \mathrm{kHz}$, respectively, to prevent aliasing. The $\mathrm{L}$ MARUs were programmed to record continuously at sample rates of 2 and $5 \mathrm{kHz}$ with an $800 \mathrm{~Hz}$ low-pass filter and a $2 \mathrm{kHz}$ low-pass filter, respectively (Table 1). Each low-pass filter reduced noise by a rate of $24 \mathrm{~dB}$ per octave above the filter corner frequency. A $10 \mathrm{~Hz}$ high-pass filter was applied to all $\mathrm{H}$ and $\mathrm{L}$ units to reduce electrical interference from the recording unit, which reduced the lowfrequency noise by a rate of $36 \mathrm{~dB}$ per octave below $10 \mathrm{~Hz}$. Data from these MARUs were extracted and converted into aiff audio files. Each unit was programmed with a gain setting of $23.5 \mathrm{~dB}$, resulting in a system sensitivity of $-145.5 \mathrm{~dB}$ re $1 \mathrm{~V} \mu \mathrm{Pa}^{-1}$, which has a flat frequency response of $\pm 3 \mathrm{~dB}$.

\section{Acoustical signal processing}

Acoustic data were processed within the SEDNA toolbox (Dugan et al. 2011) in MATLAB using a Hann window with zero overlap, a fast Fourier transform (FFT) size where $\Delta$ time $=1 \mathrm{~s}$, with a $1 \mathrm{~Hz}$ frequency

Table 1. Information from Marine Autonomous Recording Units (MARU) and geographical locations of the 7 acoustic recording sites. Dep: deployment number

\begin{tabular}{|c|c|c|c|c|c|c|c|c|c|}
\hline MARU & Dep & $\begin{array}{c}\text { Duty cycle } \\
\text { ‘on'/'off' (min) }\end{array}$ & $\begin{array}{c}\text { Sample } \\
\text { rate }(\mathrm{kHz})\end{array}$ & $\begin{array}{l}\text { Depth } \\
\text { (m) }\end{array}$ & $\begin{array}{c}\text { Latitude } \\
\left({ }^{\circ} \mathrm{N}\right)\end{array}$ & $\begin{array}{l}\text { Longitude } \\
\left({ }^{\circ} \mathrm{W}\right)\end{array}$ & $\begin{array}{c}\text { Start date } \\
\text { (mm/dd/yy) }\end{array}$ & $\begin{array}{c}\text { End date } \\
(\mathrm{mm} / \mathrm{dd} / \mathrm{yy})\end{array}$ & $\begin{array}{l}\text { Total } \\
\text { days }\end{array}$ \\
\hline \multirow[t]{2}{*}{$\mathrm{H}-1$} & 1,2 & $5.25 / 24.75$ & 8 & 967 & 27.63591 & 91.7244 & 07/04/10 & $02 / 22 / 12$ & 544 \\
\hline & 3,4 & $15 / 45$ & 20 & & & & & & \\
\hline \multirow[t]{2}{*}{$\mathrm{H}-2$} & 1,2 & $5.25 / 24.75$ & 8 & 824 & 27.85067 & 90.3878 & 07/03/10 & $02 / 27 / 12$ & 524 \\
\hline & 3,4 & $15 / 45$ & 20 & & & & & & \\
\hline \multirow[t]{2}{*}{$\mathrm{H}-3$} & 1,2 & $5.25 / 24.75$ & 8 & 883 & 28.55668 & 88.8761 & 07/07/10 & $02 / 27 / 12$ & 502 \\
\hline & 3,4 & $15 / 45$ & 20 & & & & & & \\
\hline \multirow[t]{2}{*}{$\mathrm{H}-4$} & 1,2 & $5.25 / 24.75$ & 8 & 1096 & 29.0746 & 88.0184 & $07 / 12 / 10$ & $02 / 27 / 12$ & 519 \\
\hline & 3,4 & $15 / 45$ & 20 & & & & & & \\
\hline \multirow[t]{2}{*}{ L-5 } & 1,2 & Continuous & 2 & 252 & 29.605 & 86.8817 & 06/21/10 & 09/12/11 & 307 \\
\hline & 3 & & 5 & & & & & & \\
\hline \multirow[t]{2}{*}{ H-6 } & 1,2 & $5.25 / 24.75$ & 8 & 1233 & 28.25017 & 86.8327 & $07 / 29 / 10$ & 02/28/12 & 508 \\
\hline & 3,4 & $15 / 45$ & 20 & & & & & & \\
\hline \multirow[t]{2}{*}{$\mathrm{H}-7$} & 1,2 & $5.25 / 24.75$ & 8 & 1370 & 24.79562 & 84.2756 & $07 / 30 / 10$ & $12 / 5 / 11$ & 418 \\
\hline & 3,4 & $15 / 45$ & 20 & & & & & & \\
\hline
\end{tabular}


resolution. Noise data above $4 \mathrm{kHz}$ were excluded from April 2011 through February 2012 in order to match the $8 \mathrm{kHz}$ sample rate of recordings from July 2010 through March 2011. Continuous bands of internal noise were removed through post-processing in SEDNA. Frequency-modulated internal hard-drive noise was quantified within each frequency band by calculating the differences between the mean plus a multiple of the standard deviation of the noise levels in the original frequency band and values that exceeded the original band measurements for adjacent periods of time.

\section{Equivalent sound levels}

To examine the variation in sound levels as a function of time, we used the metric of equivalent continuous sound pressure level, or $L_{\text {eq }}(\mathrm{dB}$ re $1 \mu \mathrm{Pa})$, which represents the average flat frequency-weighting sound pressure of a continuous time-varying signal (ANSI 1994) over specified time intervals. The resulting mean squared sound pressure level is expressed by:

$$
L_{\mathrm{eq}}=10 \log _{10}\left(\frac{1}{T} \int_{0}^{T} \frac{P_{\mathrm{m}}^{2}(t)}{P_{\mathrm{ref}}^{2}} \mathrm{~d} t\right)
$$

where $T$ is the time interval, $P_{\mathrm{m}}$ is the measured sound pressure, $t$ refers to time, and $P_{\text {ref }}$ is the reference pressure of $1 \mu \mathrm{Pa}$. For different aspects of this study, we measured $L_{\text {eq }}$ using 1 of 3 time intervals: $1 \mathrm{~h}$, $1 \mathrm{~min}$, or $1 \mathrm{~s}$.

\section{$1 / 3$-octave bands}

Traditional acoustic signal processing methods often divide the acoustic signal into frequency bands, which divides the spectrum into smaller individual bands (based on octaves) (e.g. Peterson \& Gross 1978). For sound analysis in a biological context, 1/3octave bands are commonly used, since the function of the mammalian ear can be approximated as a set of bandpass filters with a resolution of approximately $1 / 3$ of an octave (Richardson et al. 1995, Madsen et al. 2006). The sound data in this study were then divided into 3 frequency bands, with minimum and maximum frequencies of each band dependent on 1/3octave frequencies: a low-frequency (LF) band, with low and high normal center frequencies of 10$500 \mathrm{~Hz}$, a mid-frequency (MF) band, containing low and high normal center frequencies of 500-1000 Hz, and a high-frequency (HF) band, using low and high normal center frequencies of $1000-3150 \mathrm{~Hz}$. Since Site L-5 recorded with a sample rate of $2 \mathrm{kHz}$ from July 2010 through December 2010, the MF frequency band for that site had lower and upper normal center frequencies of 500 and $800 \mathrm{~Hz}$ due to limitations of the $1000 \mathrm{~Hz}$ Nyquist frequency.

The LF band was selected to include the environmental, meteorological, biological, and anthropogenic sounds that primarily occur below $500 \mathrm{~Hz}$ (Urick 1986, Hildebrand 2009, Roth et al. 2012). The MF band was selected to include biological and wave action sounds (peak frequency $>500 \mathrm{~Hz}$ ). The HF band was selected to include high-amplitude sperm whale foraging clicks (Backus \& Schevill 1966, Watkins 1980, Goold \& Jones 1995, Wahlberg 2002, Morrissey et al. 2006), which are some of the most acoustically significant contributors to the highfrequency ambient noise spectrum of any whale species (Cato 1992). In addition, the HF band was intended to capture high wind, wave, and precipitation noise that tend to dominate higher frequency ranges between 1 and $50 \mathrm{kHz}$ (Richardson et al. 1995, Hildebrand 2009). Separating the frequency bandwidth into these 3 bands allowed for an independent examination of environmental, biological, and anthropogenic acoustic processes within each band. $L_{\text {eq }}$ values were averaged within each frequency band over $1 \mathrm{~h}$ time slices, for a total of 24 sound measurements per day at each site across the recording period (79440 samples).

To describe general noise levels across the Gulf of Mexico within each frequency band (Table 2), we calculated the median $L_{\text {eq }}\left(L_{50}\right)$, the $L_{\text {eq }}$ that was exceeded $1 \%$ of the time $\left(L_{01}\right)$, and the $L_{\text {eq }}$ that was exceeded $99 \%$ of the time $\left(L_{99}\right)$, each averaged over a $1 \mathrm{~h}$ integration time. Percentiles that represent the lower tenth to first percentiles are commonly used to calculate $L_{\text {eq }}$ in the absence of notable anthropogenic, biological, and meteorological sound sources, referred to as 'background noise' (Cowan 1993). To estimate the background noise of each frequency band in the Gulf of Mexico, we calculated $L_{\text {eq }}$ that was exceeded $95 \%$ of the time $\left(L_{95}\right)$ for each recording site.

Pairwise correlations were performed to test the correlation of $L_{\text {eq }}(T=1 \mathrm{~h})$ among the 3 frequency bands. An analysis of variance (ANOVA) was used to test for differences in noise values among the frequency bands, followed by a Tukey honest significant difference (HSD) post hoc analysis to identify significantly different frequency bands. Statistical analyses were performed using JMP (SAS Institute). 
Table 2. $L_{\text {eq }}(\mathrm{dB}$ re $1 \mu \mathrm{Pa})$ that was exceeded $99 \%$ of the time $\left(L_{99}\right)$, median $L_{\text {eq }}\left(L_{50}\right), L_{\text {eq }}$ that was exceeded $1 \%$ of the time $\left(L_{01}\right)$ and background $L_{\mathrm{eq}}\left(L_{95}\right)$ noise levels averaged over $1 \mathrm{~h}$ time slices for each frequency band (LF: low frequency; MF: midfrequency; HF: high frequency) and recording site (see Fig. 1) throughout the study period. Note the sample rate for Site L-5 was lower than that of the H sites; therefore, there are no values for Site L-5 in the HF band. n/a: not available

\begin{tabular}{|c|c|c|c|c|c|c|c|c|c|c|c|c|}
\hline \multirow[t]{2}{*}{ Site } & \multicolumn{4}{|c|}{ LF band $(10-500 \mathrm{~Hz})$} & \multicolumn{4}{|c|}{ MF band $(500-1000 \mathrm{~Hz})$} & \multicolumn{4}{|c|}{ HF band (1000-3150 Hz) } \\
\hline & $L_{99}$ & $L_{50}$ & $L_{01}$ & $L_{95}$ & $L_{99}$ & $L_{50}$ & $L_{01}$ & $L_{95}$ & $L_{99}$ & $L_{50}$ & $L_{01}$ & $L_{95}$ \\
\hline $\mathrm{H}-1$ & 105 & 115 & 128 & 108 & 83 & 90 & 101 & 84 & 83 & 93 & 101 & 84 \\
\hline H-2 & 95 & 110 & 126 & 97 & 83 & 91 & 106 & 85 & 82 & 92 & 106 & 84 \\
\hline $\mathrm{H}-3$ & 103 & 114 & 130 & 105 & 84 & 91 & 108 & 86 & 84 & 93 & 106 & 85 \\
\hline $\mathrm{H}-4$ & 101 & 112 & 128 & 102 & 83 & 91 & 112 & 84 & 84 & 94 & 111 & 86 \\
\hline L-5 & 92 & 102 & 117 & 93 & 81 & 84 & 95 & 81 & $\mathrm{n} / \mathrm{a}$ & $\mathrm{n} / \mathrm{a}$ & $\mathrm{n} / \mathrm{a}$ & $\mathrm{n} / \mathrm{a}$ \\
\hline H-6 & 102 & 114 & 123 & 103 & 81 & 87 & 99 & 82 & 82 & 92 & 100 & 83 \\
\hline $\mathrm{H}-7$ & 89 & 110 & 123 & 92 & 82 & 90 & 103 & 84 & 86 & 94 & 104 & 87 \\
\hline Median & 101 & 112 & 126 & 102 & 83 & 90 & 103 & 84 & 83 & 93 & 105 & 85 \\
\hline
\end{tabular}

\section{Long-term spectrograms}

Visual inspection of the sound data was conducted using long-term spectrograms. Long-term spectrograms provide a broad view into ambient noise conditions over large time-scales, and allow for a general evaluation of spectral and temporal noise trends. Sound data are presented as a function of frequency and time. To represent the acoustic data for the entire study period, spectrograms were created using a 1/3octave band frequency scale along the $y$-axis and averaged over a $1 \mathrm{~h}$ integration time along the $x$-axis for each recording site. In the case of the $\mathrm{H}$ units, the $1 \mathrm{~h}$ integration time interval includes only the dutycycled sound recorded within the hour. To more closely investigate targeted sound sources on a shorter time scale, additional spectrograms were generated using a linear frequency scale and an integration time of $1 \mathrm{~s}$. Two $1 / 3$-octave frequency bands were selected to encompass as much of the recorded frequency range as possible in the spectrograms: $10-3550 \mathrm{~Hz}$ for $\mathrm{H}$ MARUs and 10-2240 Hz for L MARUs.

\section{Spectral trends}

To statistically evaluate the sound pressure levels across the entire frequency spectrum at each recording site, we generated a power spectral density (PSD) plot. The PSD captures long-term variation in ambient noise across the measured frequency domain by representing power spectra ( $\mathrm{dB}$ re $1 \mu \mathrm{Pa}^{2}$ $\mathrm{Hz}^{-1}$ ) as a function of frequency using linearly averaged 1 s sound data and a $1 \mathrm{~Hz}$ frequency resolution (similar to Samuel et al. 2005, Roth et al. 2012). Here, data from the entire recording period for each site are represented using the median percentiles of the PSD.

\section{Cumulative percent distribution}

The cumulative percent distribution was computed for each recording site and frequency band, which represents the percentage of time that sound pressure levels reached a particular $L_{\mathrm{eq}}(\mathrm{dB}$ re $1 \mu \mathrm{Pa})$, averaged over $1 \mathrm{~s}$ time intervals and using a frequency resolution of $1 \mathrm{~Hz}$. The cumulative percent distribution allows for a direct comparison of the statistical noise characteristics of each site within each of the 3 frequency bands.

\section{Temporal trends}

To demonstrate temporal variation of $L_{\mathrm{eq}}(\mathrm{dB}$ re $1 \mu \mathrm{Pa}$ ) at each recording site throughout the recording period, we plotted a time-series of $L_{\text {eq }}$ averaged over $1 \mathrm{~h}$ time intervals for each frequency band. To determine if there was an overall increase or decrease in $L_{\text {eq }}$ throughout the duration of this study, we performed a linear regression of hourly $L_{\text {eq }}$ against date for each frequency band. To evaluate general monthly trends, we averaged hourly $L_{\text {eq }}$ from each site by the month in which they occurred and performed a 1-way ANOVA to test for significant differences between months. To evaluate diel periodicity, we performed a 1-way ANOVA using $L_{\text {eq }}$ averaged over $1 \mathrm{~h}$ time intervals for each site by the hour in which the sounds were recorded $(0-23)$ for each frequency band. All statistical analyses were performed using JMP (SAS Institute).

\section{Noise contribution of distinguishable sound sources}

Environmental noise generated by precipitation and wind, anthropogenic activities, and biologically 
produced sounds ensonify many marine ecosystems. To evaluate the contribution that such events had on the ambient noise environment in the northern Gulf of Mexico, we compared $L_{\text {eq }}$ against measured wind speed values, measured $L_{\text {eq }}$ during days with seismic survey activities, and measured $L_{\text {eq }}$ during days with sperm whale foraging clicks.

Since wind speed has been documented to influence ocean ambient noise spectra at varying depths (Guerra et al. 2011), we correlated $L_{\mathrm{eq}}$ averaged over $1 \mathrm{~h}$ time intervals with wind speed data for each frequency band at each recording site. Historic wind speed measurements were obtained from satellite data collected by NASA between 4 July 2010 and 31 December 2011 (http://opendap.jpl.nasa.gov:80/ opendap/allData/ccmp/L3.0/flk). Wind speed was collected once every $6 \mathrm{~h}$; therefore, only the $L_{\text {eq }}$ from each corresponding hour was used in a linear regression, performed in JMP (SAS Institute).

Noise produced by geophysical seismic surveys includes sounds from airgun pulses, as well as the survey vessel and associated survey boats. To understand the noise contribution that seismic airgun surveys can have in the Gulf of Mexico ambient noise environment, we measured $L_{\mathrm{eq}}$ within each band (averaged over $60 \mathrm{~s}$ time intervals) for 5 'seismic' days. We defined a seismic day by the presence of spectrographically and audibly distinguishable seismic airgun pulses occurring in all $24 \mathrm{~h}$ of the recording day, as well as the absence of distinguishable transient ship noise, sperm whale clicks, and other discernable noise unrelated to seismic survey events during at least $20 \mathrm{~h}$ of the day. Since it is difficult to identify non-transient ship noise that was unrelated to the survey, we did not exclude non-transient ship noise from this analysis. Selected days were first identified using the long-term spectrograms, then confirmed by reviewing spectrograms and waveforms in intervals of $600 \mathrm{~s}$ using a linear frequency band from 10-4000 Hz, with an FFT of 2048 using Raven Pro sound analysis software (Bioacoustics Research Program 2015). Seismic days were further corroborated by seismic survey activity records from US regulatory agencies (www.data.bsee.gov). The $L_{50}$ for those days were used for comparison against days with sperm whale foraging clicks.

Sperm whales have been documented to significantly contribute to the ambient noise environment in deep water ecosystems (Cato 1992), particularly in frequencies above $1000 \mathrm{~Hz}$. We therefore characterized noise levels from $5 \mathrm{~d}$ with sperm whale foraging clicks, in which sperm whale clicks occurred during at least $20 \mathrm{~h}$ of the day and prominent anthropogenic activities occurred in $<4 \mathrm{~h}$ of the day. We defined these $5 \mathrm{~d}$ as 'sperm whale' days. $L_{\text {eq }}$ values were averaged over $60 \mathrm{~s}$ time intervals. Sperm whale foraging clicks were identified using spectrographic analysis $(0-4 \mathrm{kHz}, \mathrm{FFT}=1024,50 \%$ overlap, $180 \mathrm{~s}$ page length).

Spectral comparisons between seismic days and sperm whale days were made using a spectral probability density plot as described by Merchant et al. (2013), which provides a visualization of statistical distributions of sound levels averaged over $1 \mathrm{~s}$ time intervals using a frequency resolution of $1 \mathrm{~Hz}$.

\section{RESULTS}

In total, 79440 hourly sound measurements (3310 d) were computed from the 7 recording sites. Long-term ambient noise analysis confirmed variation in temporal, spatial, and spectral patterns of noise characteristics across the northeastern Gulf of Mexico between July 2010 and February 2012.

\section{Equivalent sound levels}

Overall, $L_{\mathrm{eq}}(T=1 \mathrm{~h})$ was highest in the LF band and lowest in the MF band (Fig. 2). Within the LF band, Site L-5 recorded the lowest $L_{50}(102 \mathrm{~dB}$ re $1 \mu \mathrm{Pa}$ ), and Site $\mathrm{H}-1$ recorded the highest $L_{50}$ $(115 \mathrm{~dB})$. The $L_{01}$ in the LF band exceeded $120 \mathrm{~dB}$ at each site except L-5, while the maximum $L_{\text {eq }}$ exceeded $130 \mathrm{~dB}$ at each site due to seismic airgun pulses (visually confirmed in spectrograms). In the MF band, Site L- 5 had the lowest $L_{50}(84 \mathrm{~dB})$. Sites $\mathrm{H}-2, \mathrm{H}-3$, and $\mathrm{H}-4$ recorded the highest $L_{50}$ of $91 \mathrm{~dB}$. In the HF band, Sites H-2 and H-6 recorded the lowest $L_{50}(92 \mathrm{~dB})$, and Site $\mathrm{H}-4$ recorded the highest $L_{50}(94 \mathrm{~dB})$. Background noise $\left(L_{95}\right)$ levels in the $\mathrm{LF}$ band had a median of $102 \mathrm{~dB}$, and the MF band and HF band had median noise values of 84 and $85 \mathrm{~dB}$, respectively. Median $L_{\text {eq }}$ values in the LF band $(112 \mathrm{~dB})$ were higher than in the MF (90 dB) and HF $(93 \mathrm{~dB})$ bands, particularly during time periods with seismic airgun pulses (Fig. 3). Pairwise correlations (performed using JMP; SAS Institute) revealed that the MF and HF bands were highly correlated $(\mathrm{r}=$ $0.8, \mathrm{p}<0.0001)$. The LF band was weakly correlated to the MF band $(r=0.28, p<0.001)$ and the HF band $(\mathrm{r}=-0.08, \mathrm{p}<0.0001)$. An ANOVA of $L_{\mathrm{eq}}$ yielded significant variation among the frequency bands $\left(F=279035.3, \mathrm{df}=2, \mathrm{R}^{2}=0.71, \mathrm{p}<0.0001\right)$. A Tukey HSD analysis showed that $L_{\text {eq }}$ within each 


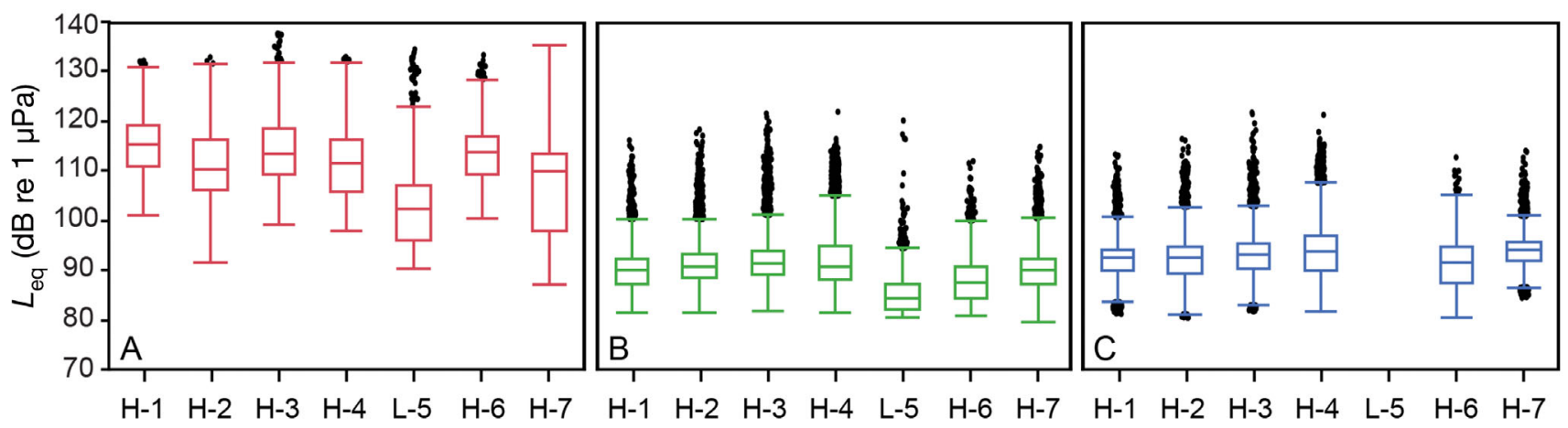

Fig. 2. Distribution of equivalent continuous sound pressure level $\left(L_{\mathrm{eq}}\right)(\mathrm{dB}$ re $1 \mu \mathrm{Pa}$ ) values averaged over $1 \mathrm{~h}$ time intervals for each recording site throughout the study period for each frequency band: (A) low frequency (10-500 Hz), (B) mid-frequency $(500-1000 \mathrm{~Hz})$, and (C) high frequency $(1000-3150 \mathrm{~Hz})$. Each boxplot represents the median $L_{\mathrm{eq}}$ and first and third quartiles. The error bars illustrate 1.5 of the interquartile range, and the points represent outliers

frequency band were significantly different $(\mathrm{p}<$ 0.0001) from one another.

Frequency-modulated internal hard-drive noise was only recorded during the first 2 MARU deployment periods (July 2010-May 2011). Internal noise was not recorded in the LF or MF frequency band for the $\mathrm{H}$ sites. The median $L_{\text {eq }}(T=1 \mathrm{~h})$ of internal noise recorded in the $\mathrm{HF}$ band for $\mathrm{H}$ sites was $1.3 \mathrm{~dB}$. Since Site L-5 did not record in the HF band, internal noise measured a median $L_{\mathrm{eq}}$ of $0.6 \mathrm{~dB}$ within the MF band. These low contributions to the recorded $L_{\text {eq }}$ did not greatly influence the reported $L_{\text {eq }}$ trends within the MF and HF bands.

\section{Long-term spectrograms}

The $1 / 3$-octave band spectrograms illustrate persistent shipping and seismic survey activities throughout the northern Gulf of Mexico during the study (Fig. 3), represented by the warm colors between 10 and $500 \mathrm{~Hz}$. A distinguishable seismic survey occurred for 2 mo between 18 October and 25 December 2010, which is visible on the spectrograms at all sites except $\mathrm{H}-1$, evident by the temporal pattern of elevated noise levels (Fig. 3). The same seismic survey at Site $\mathrm{H}-3$ is presented in a series of spectrograms of differing time scales with a linear frequency scale in Fig. 4. During that seismic survey, $L_{50}$ values $(T=1 \mathrm{~h})$ were highest at Sites H-3 (121 dB re $1 \mu \mathrm{Pa}), \mathrm{H}-4$ (115 dB), and H-6 (115 dB), suggesting that the survey was operating within or near the Mississippi Canyon. Seismic pulses from that survey are faintly visible at Sites H-2 and H-7, where $L_{50}$ measured 109 and $98 \mathrm{~dB}$, respectively. Seismic airgun pulses were recorded roughly every $10 \mathrm{~s}$ for a large portion of the survey, but varied throughout the study, confirmed by spectrographic analysis. Also visible in the spectrograms are several storm events, evident by the warm colors above $800 \mathrm{~Hz}$. Seismic and shipping noise appear to have temporarily decreased or stopped due to Tropical Storm Lee between 1 and 6 September 2011. During this time period noise levels above $1 \mathrm{kHz}$ at each site increased and noise below $500 \mathrm{~Hz}$ decreased, suggesting a temporary decrease in anthropogenic activity.

\section{Spectral trends}

Median PSD levels among all sites for the entire study period showed similar trends as a function of frequency (Fig. 5). Location L-5 displayed a different trend, where the power spectrum decreased between 30 and $300 \mathrm{~Hz}$, and increased slightly above $400 \mathrm{~Hz}$. Higher power spectra levels below $100 \mathrm{~Hz}$ at all sites are likely attributed to shipping and seismic noise, where median power spectral density for each site ranged between $85 \mathrm{~dB}$ (re $1 \mu \mathrm{Pa}^{2} \mathrm{~Hz}^{-1}$ ) and $100 \mathrm{~dB}$. Site H-6 recorded the lowest power spectra values of the high-frequency units above $300 \mathrm{~Hz}$, yet the second highest below $80 \mathrm{~Hz}$.

The median power spectrum for L-5 displayed a spike around 80 and $100 \mathrm{~Hz}$, possibly due to internal noise from the hard drive that was not removed during post-processing, but was low enough to not influence median noise measurements within the LF band. MARU self-noise was also visible in frequency bands above $1000 \mathrm{~Hz}$ for each site, which were quantified earlier in the results. Continuous, external, mechanical noise was evident at all sites except H-1 and H-7 (likely due to ocean currents), represented by the peak in the percentile curves around $200 \mathrm{~Hz}$ and confirmed during spectrographic analysis. 


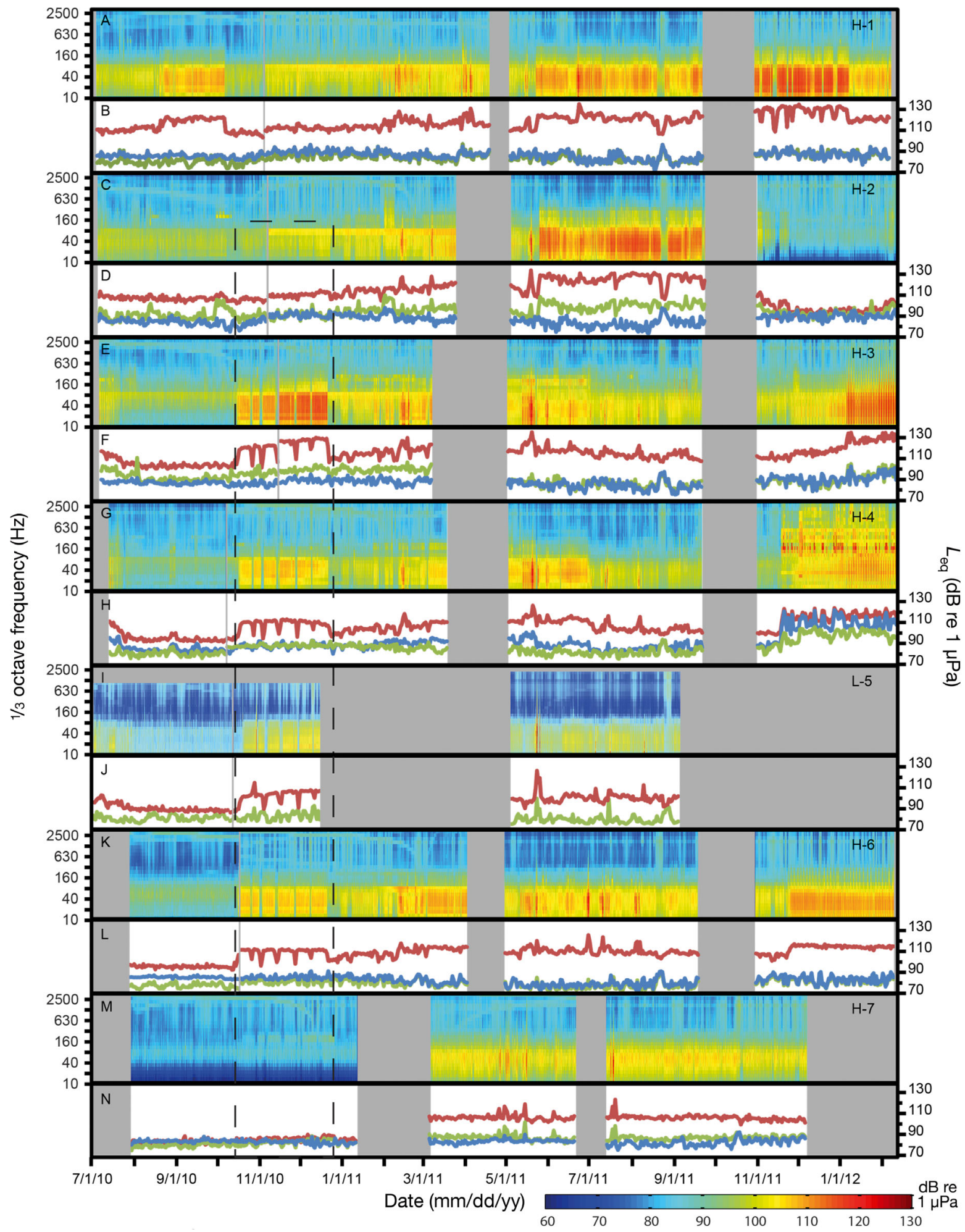

Fig. 3. The $1 / 3$-octave long-term spectrograms $(A, C, E, G, I, K, M)$ of the measured sound levels for each of the 7 recording sites, in order from west to east (fast Fourier transform size $=1 \mathrm{~s}$, overlap $=0 \mathrm{~s}$, Hann window) averaged over $1 \mathrm{~h}$ time intervals, with a $1 \mathrm{~Hz}$ frequency resolution. Below each spectrogram $(\mathrm{B}, \mathrm{D}, \mathrm{F}, \mathrm{H}, \mathrm{J}, \mathrm{L}, \mathrm{N})$ is a corresponding time-series representing $L_{\mathrm{eq}}(\mathrm{dB}$ re $1 \mu \mathrm{Pa})$ over time for the low-frequency band (10-500 Hz; red line), mid-frequency band (500-1000 Hz; green line), and high-frequency band $\left(1000-3150 \mathrm{~Hz}\right.$; blue line). $L_{\text {eq }}$ values are indicated along the secondary $y$-axis. Black dashed lines mark a seismic survey recorded across multiple sites. The areas in gray indicate time periods or frequencies where sound was not recorded 


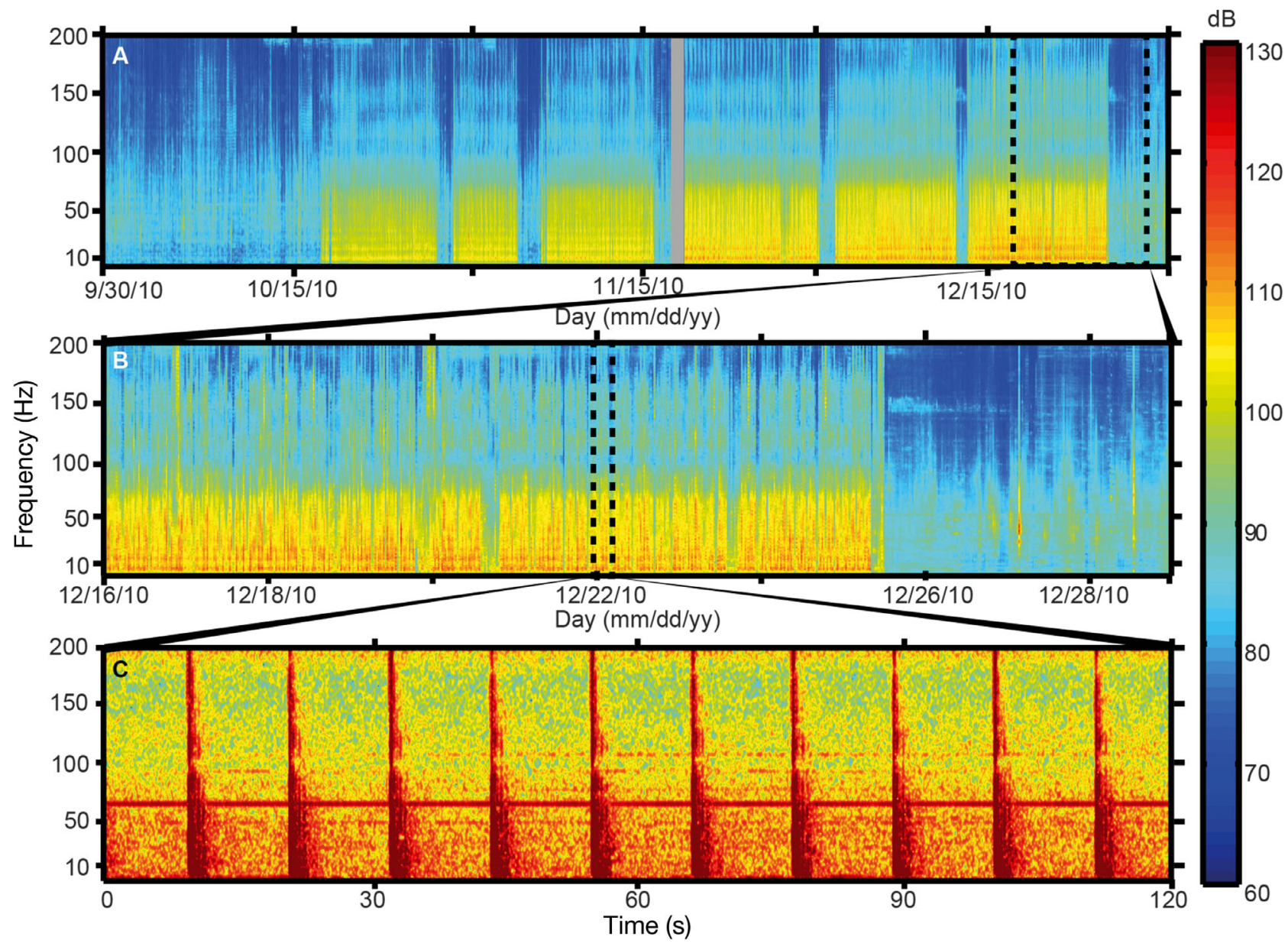

Fig. 4. Spectrograms illustrating 3 time spans in which a seismic survey was recorded at Site H-3 (fast Fourier transform size = $1 \mathrm{~s}$, overlap $=0 \mathrm{~s}$, Hann window): (A) 3 mo of $L_{\mathrm{eq}}(\mathrm{dB}$ re $1 \mu \mathrm{Pa}$ ) data between 30 September 2010 and 30 December 2010, (B) 2 wk of $L_{\text {eq }}$ data between 16 and 30 December 2010, and (C) a 2 min time period within the first hour of 22 December 2010, where individual seismic airgun pulses and associated reverberation are visible. The color map represents $L_{\mathrm{eq}}(\mathrm{dB}$ re $1 \mu \mathrm{Pa}$ ). An averaging time of $1 \mathrm{~s}$ time intervals and frequency resolution of $1 \mathrm{~Hz}$ were used for each spectrogram

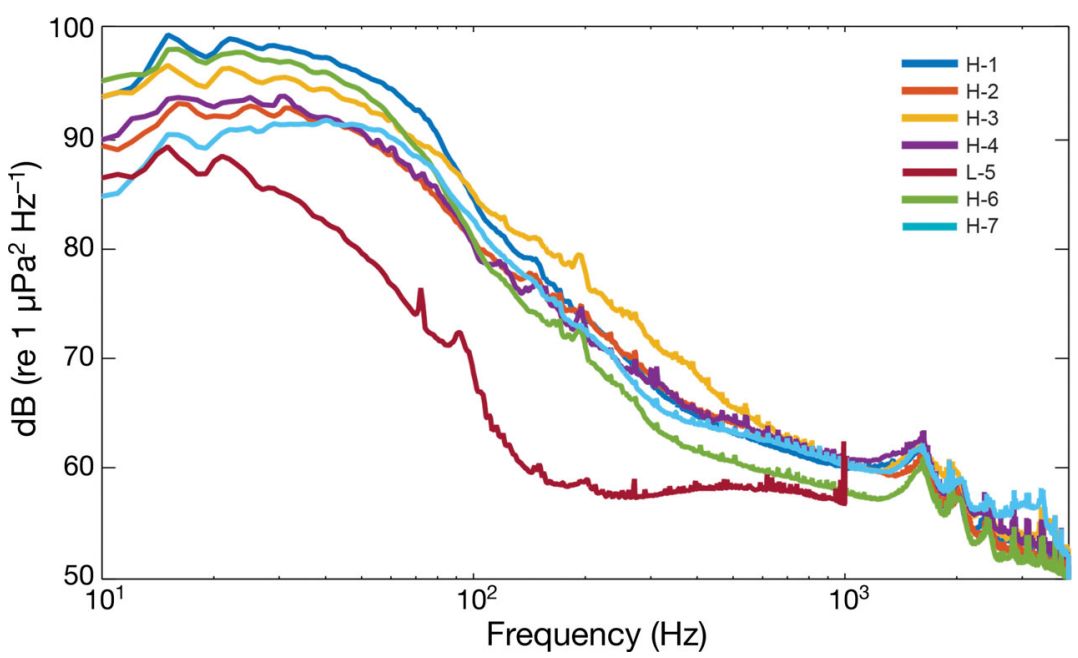

Fig. 5. Power spectral density of sound levels $\left(\mathrm{dB}\right.$ re $\left.1 \mu \mathrm{Pa}^{2} \mathrm{~Hz}^{-1}\right)$ of the $50^{\text {th }}$ percentiles for the 7 study sites throughout the recording period averaged over $1 \mathrm{~s}$ time intervals

\section{Cumulative percent distribution}

The cumulative percent distribution of $L_{\mathrm{eq}}(T=1 \mathrm{~s})$ is illustrated in Fig. 6. The LF band showed the most variable sound level distributions of the 3 bands (Fig. 6C). Site L-5 recorded the lowest $L_{\text {eq }}$, where levels occurred above $96 \mathrm{~dB}$ (re $1 \mu \mathrm{Pa}$ ) during $50 \%$ of the recording period, while Sites H-1 and $\mathrm{H}-6$ recorded $L_{\text {eq }}$ above $110 \mathrm{~dB}$ $50 \%$ of the time. During $10 \%$ of the recording period, L-5 recorded $L_{\text {eq }}$ above $106 \mathrm{~dB}$ and $\mathrm{H}-1$ recorded $L_{\mathrm{eq}}$ above $120 \mathrm{~dB}$. Percentile distributions in the MF band varied less among sites (Fig. 6B). Site L-5, again, recorded lower $L_{\mathrm{eq}}$ more often than the other 


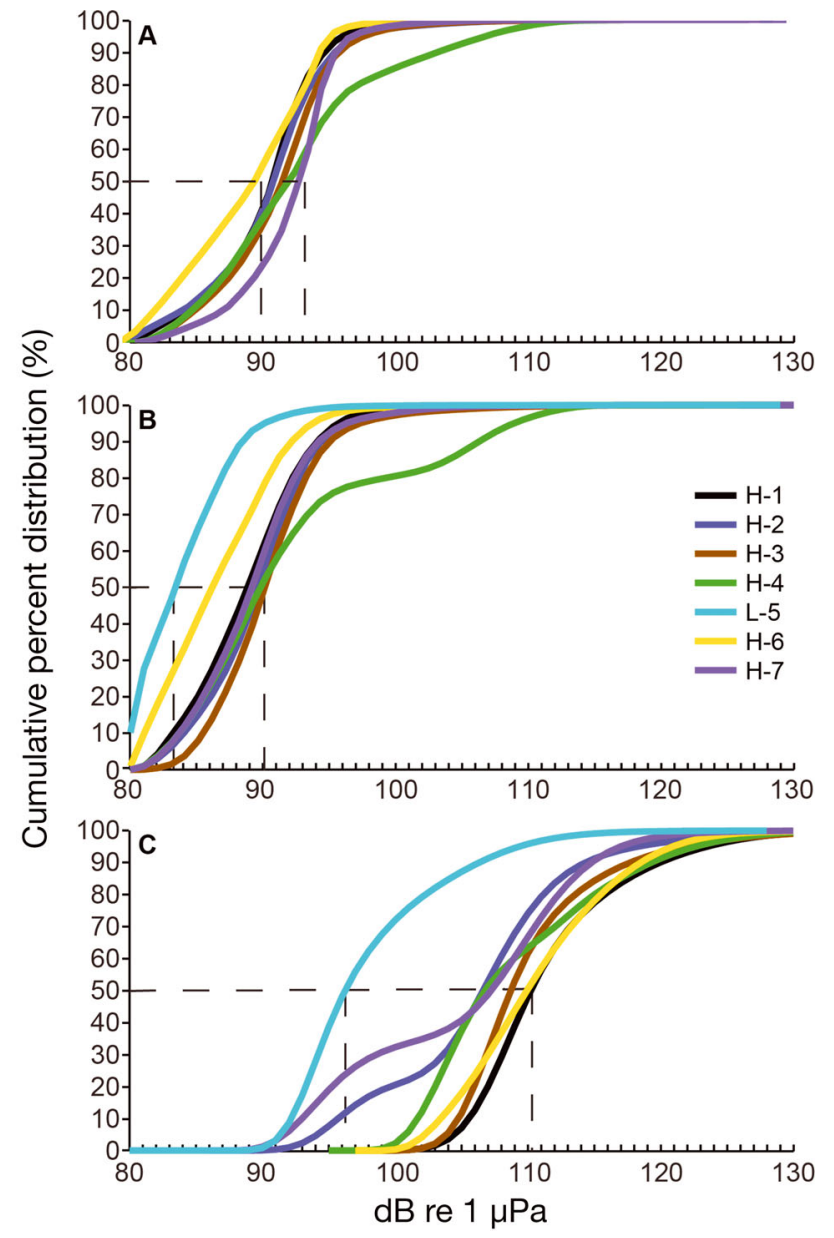

Fig. 6. Cumulative percent distribution of $L_{\mathrm{eq}}(\mathrm{dB}$ re $1 \mu \mathrm{Pa})$ averaged over $1 \mathrm{~s}$ time intervals for each recording site in the 3 frequency bands: (A) HF band $(1000-3150 \mathrm{~Hz})$, (B) MF band $(500-1000 \mathrm{~Hz})$, and (C) LF band (10-500 Hz). Dashed lines represent the intersection between $50 \%$ of recording time and $L_{\text {eq }}$ of sites with the highest and lowest $L_{\mathrm{eq}}$

sites, with a $L_{\text {eq }}$ above $83 \mathrm{~dB}$ during $50 \%$ of the recording. Sites H-3 and H-4 recorded $L_{\text {eq }}$ above $90 \mathrm{~dB}$ $50 \%$ of the time. During $10 \%$ of the recording period, Site L- 5 noise values were above $88 \mathrm{~dB}$ and at $\mathrm{H}-4 L_{\mathrm{eq}}$ values were above $106 \mathrm{~dB}$. All sites exhibited relatively similar percentile distributions in the HF band (Fig. 6A), where $L_{\text {eq }}$ values were above $90 \mathrm{~dB} 50 \%$ of the time. Five sites recorded $L_{\text {eq }}$ above $95 \mathrm{~dB} 10 \%$ of the time; however, $\mathrm{H}-4$ recorded levels above $95 \mathrm{~dB}$ approximately $30 \%$ of the recording time.

\section{Temporal trends}

The LF band had the most dynamic temporal variation throughout the study period, and $L_{\text {eq }}(T=1 \mathrm{~h})$, illustrated in Fig. 3. A linear regression showed no strong trends between $L_{\text {eq }}$ and time throughout the study for any frequency band (LF: slope $=0.0161$, $\mathrm{R}^{2}=0.13, \mathrm{p}<0.0001 ; \mathrm{MF}$ : slope $=0.0004, \mathrm{R}^{2}=0.021$ ， $\mathrm{p}<0.0001 ;$ HF: slope $=-0.0003, \mathrm{R}^{2}=0.016, \mathrm{p}<$ $0.0001)$.

The $L_{\text {eq }}$ values were highly variable within each month. An ANOVA of $L_{\mathrm{eq}}$ per month revealed that $L_{\text {eq }}$ values in each month are statistically different in the LF band $\left(F=689.7\right.$, df $\left.=11, \mathrm{R}^{2}=0.087, \mathrm{p}<0.001\right)$, the $\mathrm{MF}$ band $\left(F=1195.3\right.$, df $=11, \mathrm{R}^{2}=0.142$, $\mathrm{p}<$ $0.001)$, and the HF band $\left(F=869.1, \mathrm{df}=11, \mathrm{R}^{2}=0.117\right.$, $\mathrm{p}<0.001)$. The mean monthly $L_{\text {eq }}(T=1 \mathrm{~h})$ decreased at each site within the MF and HF bands between the months of April and July, and increased between September and January (Fig. 7). In the LF band, noise levels were lowest between July and October and highest between November and March at Sites $\mathrm{H}-3, \mathrm{H}-4, \mathrm{~L}-5$, and H-6. These trends coincide with the hurricane season in the Gulf of Mexico, where the HF and MF bands are expected to be higher due to increased precipitation and wave action, and the LF band lower, due to a reduction in anthropogenic activities during storm events. In contrast, noise levels at Sites H-2 and H-7 were lowest in December and highest between March and August.

There were no clear trends between $L_{\text {eq }}$ and hour in the LF band $\left(F=0.515\right.$, df $=23, \mathrm{R}^{2}=0.0001, \mathrm{p}<$ $0.9729)$, the $\mathrm{MF}$ band $\left(F=1.755, \mathrm{df}=23, \mathrm{R}^{2}=0.0005\right.$, $\mathrm{p}<0.014)$, or the HF band $\left(F=2.788, \mathrm{df}=23, \mathrm{R}^{2}=\right.$ $0.0009, \mathrm{p}<0.001)$. Factoring in month or recorder depth did not appear to improve significance; therefore, diel periodicity was not evident.

\section{Noise contribution of distinguishable sound sources}

A total of $12096 \mathrm{~h}$ were used to examine the relationship between wind speed and $L_{\text {eq }}(T=1 \mathrm{~h})$. Using a linear regression analysis, wind speed was not found to be strongly correlated with $L_{\mathrm{eq}}$ in the LF band, possibly due to the dominant anthropogenic noise in that frequency band, but was positively correlated with $L_{\text {eq }}$ in the MF band and the HF band (Table 3). Wind speed had the strongest relationship to $L_{\mathrm{eq}}$ in the MF band at Site L-5 $\left(\mathrm{R}^{2}=0.59, \mathrm{p}<\right.$ $0.0001)$ and Site H-6 $\left(R^{2}=0.64, p<0.0001\right)$. In the HF band, the strongest relationship occurred at Sites H-1 $\left(\mathrm{R}^{2}=0.31, \mathrm{p}<0.0001\right)$ and H-6 $\left(\mathrm{R}^{2}=0.35, \mathrm{p}<0.0001\right)$. The MF and HF frequency bands exhibited similar correlations when $L_{\mathrm{eq}}$ values were aggregated within each band. The linear relationship between $L_{\mathrm{eq}}$ and 


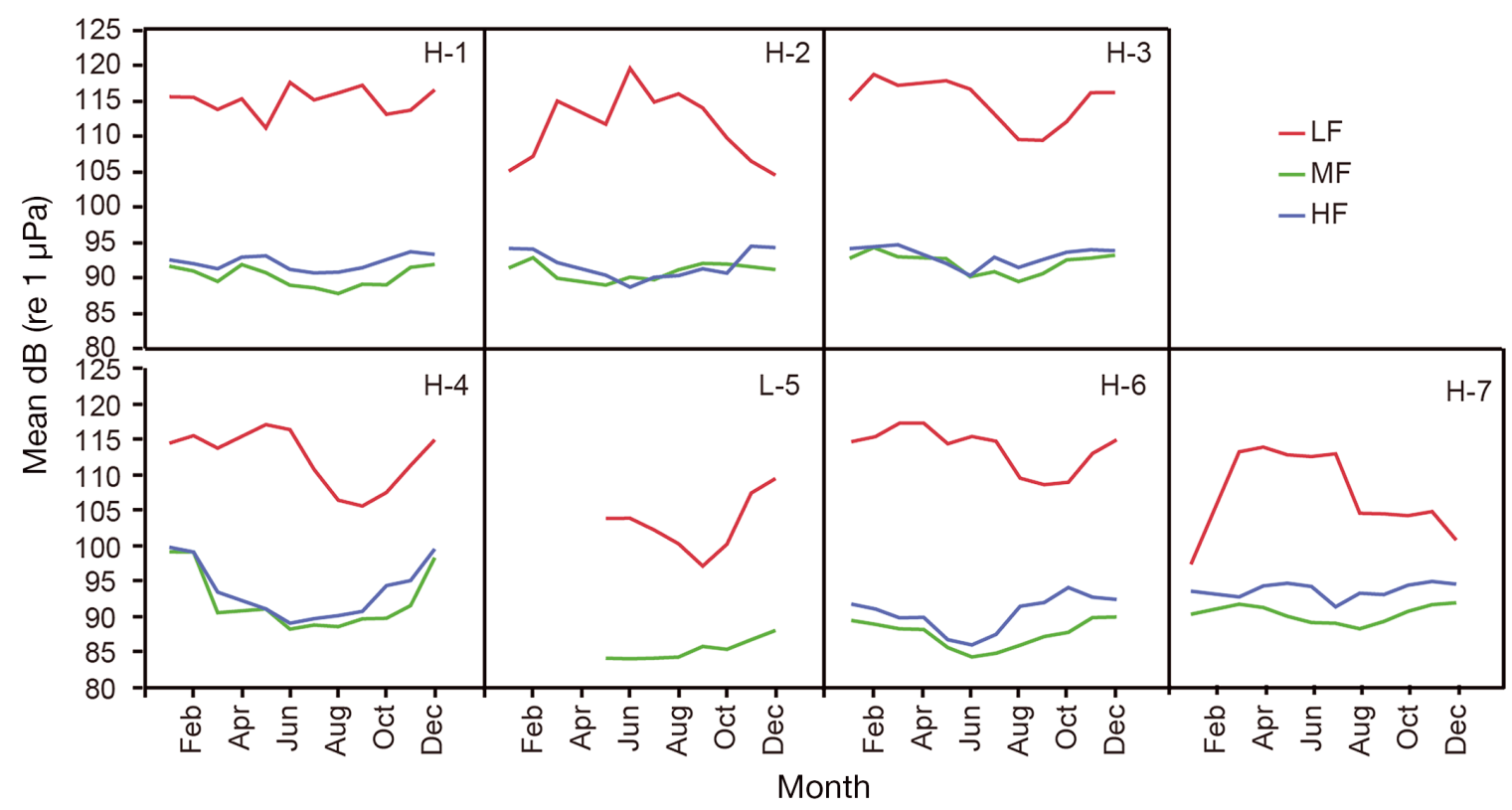

Fig. 7. Mean $L_{\text {eq }}(\mathrm{dB}$ re $1 \mu \mathrm{Pa})$ values averaged over $1 \mathrm{~h}$ time intervals for each frequency band by month per site. Frequency bands represented are the low-frequency (LF) band (10-500 Hz), mid-frequency (MF) band (500-1000 Hz), and high-frequency (HF) band $(1000-3150 \mathrm{~Hz})$

depth of the MARU was weak in the LF (intercept = 106.75, slope $\left.=0.004, \mathrm{R}^{2}=0.036, \mathrm{p}<0.0001\right)$, MF (intercept $=88.72$, slope $=0.001, \mathrm{R}^{2}=0.008, \mathrm{p}<$ 0.0001 ), and HF (intercept $=93.67$, slope $=-0.001$, $\mathrm{R}^{2}=0.002, \mathrm{p}<0.0001$ ) bands.

The dates identified as seismic days occurred between 15 and 19 December 2011 at Site H-1. It was confirmed that a 3-dimensional ocean bottom node seismic survey was conducted between 28 September 2011 and 25 January 2012 within the Garden Banks lease block area (www.data.bsee.gov), within which Site H-1 was located. The median $L_{\text {eq }}(T=60 \mathrm{~s})$ in the LF band was $124 \mathrm{~dB}$ (re $1 \mu \mathrm{Pa}$ ), which is $12 \mathrm{~dB}$ higher than the $L_{50}$ across all sites throughout the study period (Table 4). $L_{99}$ and $L_{01}$ were 118 and $133 \mathrm{~dB}$, re- spectively. $L_{50}$ in the MF and HF bands was 92 and $91 \mathrm{~dB}$, respectively. Additionally, power levels were higher below $100 \mathrm{~Hz}$ during the seismic days than the sperm whale days without seismic activities (Fig. 8).

The dates selected as sperm whale days occurred between 14 and 18 September 2010 at Site H-6. The median $L_{\mathrm{eq}}(T=60 \mathrm{~s})$ in the LF, MF, and HF bands were 111,89 , and $96 \mathrm{~dB}$, respectively. $L_{50}$ values were approximately $4 \mathrm{~dB}$ higher during sperm whale days than during seismic days in the HF band. In the LF band, $L_{50}$ was $13 \mathrm{~dB}$ higher during seismic days than during sperm whale days. The power spectral density ( $\mathrm{dB}$ re $1 \mathrm{\mu Pa}^{2} \mathrm{~Hz}^{-1}$ ) was flat between 400 and $1000 \mathrm{~Hz}$ from sperm whale foraging clicks, unlike the seismic days (Fig. 8).

Table 3. Linear regression of $L_{\text {eq }}\left(\mathrm{dB}\right.$ re $1 \mu \mathrm{Pa}$ ) averaged over $1 \mathrm{~h}$ time intervals with mean hourly wind speed (m s $\mathrm{s}^{-1}$ ) at each recording site and for all sites combined. Depth refers to the depth of the recording unit at each site. A p-value $<0.05$ was significant. n/a: not applicable

\begin{tabular}{|c|c|c|c|c|c|c|c|c|c|c|c|}
\hline \multirow[t]{2}{*}{ Site } & \multirow{2}{*}{$\begin{array}{l}\text { Depth } \\
\text { (m) }\end{array}$} & \multirow{2}{*}{$\begin{array}{c}\text { Mean } \pm \text { SD of } \\
\text { wind speed }\left(\mathrm{m} \mathrm{s}^{-1}\right)\end{array}$} & \multicolumn{3}{|c|}{ LF band $(10-500 \mathrm{~Hz})$} & \multicolumn{3}{|c|}{ MF band $(500-1000 \mathrm{~Hz})$} & \multicolumn{3}{|c|}{$\mathrm{HF}$ band $(1000-3150 \mathrm{~Hz}$} \\
\hline & & & Slope & $\mathrm{p}$-value & $\mathrm{R}^{2}$ & Slope & $\mathrm{p}$-value & $\mathrm{R}^{2}$ & Slope & $\mathrm{p}$-value & $\mathrm{R}^{2}$ \\
\hline $\mathrm{H}-1$ & 965 & $5.9 \pm 3.1$ & -0.257 & $<0.0001$ & 0.02 & 0.7595 & $<0.0001$ & 0.36 & 0.6922 & $<0.0001$ & 0.31 \\
\hline $\mathrm{H}-2$ & 831 & $6.3 \pm 3.5$ & -0.734 & $<0.0001$ & 0.13 & 0.4522 & $<0.0001$ & 0.14 & 0.7095 & $<0.0001$ & 0.27 \\
\hline $\mathrm{H}-3$ & 888 & $6.4 \pm 3.4$ & -0.106 & 0.01 & 0 & 0.4701 & $<0.0001$ & 0.15 & 0.5619 & $<0.0001$ & 0.2 \\
\hline $\mathrm{H}-4$ & 1054 & $6.1 \pm 3.5$ & -0.046 & 0.2791 & 0 & 0.785 & $<0.0001$ & 0.24 & 0.7642 & $<0.0001$ & 0.26 \\
\hline L-5 & 250 & $5.3 \pm 2.8$ & 0.057 & 0.3759 & 0 & 0.9577 & $<0.0001$ & 0.59 & $\mathrm{n} / \mathrm{a}$ & $\mathrm{n} / \mathrm{a}$ & $\mathrm{n} / \mathrm{a}$ \\
\hline H-6 & 1460 & $5.8 \pm 3.2$ & -0.234 & $<0.0001$ & 0.02 & 1.0346 & $<0.0001$ & 0.64 & 0.8488 & $<0.0001$ & 0.35 \\
\hline $\mathrm{H}-7$ & 1370 & $6.1 \pm 2.8$ & -0.352 & $<0.0001$ & 0.01 & 0.7664 & $<0.0001$ & 0.24 & 0.5193 & $<0.0001$ & 0.18 \\
\hline All sites & & $6.0 \pm 3.2$ & -0.199 & $<0.0001$ & 0.01 & 0.7653 & $<0.0001$ & 0.27 & 0.695 & $<0.0001$ & 0.26 \\
\hline
\end{tabular}


Table 4. $L_{\mathrm{eq}}(\mathrm{dB}$ re $1 \mu \mathrm{Pa})$ that was exceeded $99 \%$ of the time $\left(L_{99}\right)$, median $L_{\mathrm{eq}}$ $\left(L_{50}\right), L_{\text {eq }}$ that was exceeded $1 \%$ of the time $\left(L_{01}\right)$, and background $L_{\text {eq }}\left(L_{95}\right)$ noise levels averaged over 1 min time intervals for each frequency band during $5 \mathrm{~d}$ with seismic pulses and $5 \mathrm{~d}$ with sperm whale foraging clicks

\begin{tabular}{|cccccccc|}
\hline & \multicolumn{3}{c}{ Seismic pulses } & \multicolumn{3}{c|}{ Sperm whale foraging clicks } \\
\cline { 2 - 4 } & \multicolumn{2}{c}{ LF (10- } & MF (500- & HF (100- & & LF (10- & MF (500- \\
& $500 \mathrm{~Hz})$ & $1000 \mathrm{~Hz})$ & $3150 \mathrm{~Hz})$ & $500 \mathrm{~Hz})$ & $1000 \mathrm{~Hz})$ & $3150 \mathrm{~Hz})$ \\
\hline$L_{99}$ & 118 & 84 & 82 & 106 & 86 & 95 \\
$L_{50}$ & 124 & 91 & 92 & 111 & 89 & 96 \\
$L_{01}$ & 133 & 106 & 97 & 114 & 103 & 106 \\
$L_{95}$ & 121 & 86 & 83 & 107 & 87 & 95 \\
\hline
\end{tabular}

Not surprisingly, recording sites positioned nearest to high-density shipping lanes that lead to the Port of South Louisiana (H-3) and the Port of Houston (H-1) recorded the highest $L_{01}$ values $(T=1 \mathrm{~h})$ of 130 and $128 \mathrm{~dB}$, respectively. Site $\mathrm{H}-4$ is not positioned near major shipping lanes, yet it also recorded an $L_{01}$ value of $128 \mathrm{~dB}$ in the LF band. Seismic surveys occurred persistently within the De Soto Canyon and Lloyd Ridge (www.data.bsee.gov) areas throughout this study, and are possibly the primary source of higher ambient noise levels at Site H-4.

\section{DISCUSSION}

Ambient noise measurements provide a mechanism by which to sample the cumulative acoustic activity of an ecosystem, and holistically evaluate biotic, environmental, and human-induced acoustic contributions to the overall noise environment. Our results present the Gulf of Mexico as a spectrally, temporally, and spatially dynamic ambient noise environment. These data further illustrate the specific acoustic contributions of wind speed, anthropogenic activities, and sperm whale foraging clicks at different frequency bands on a large temporal and spatial scale. Though wind speed was a statistically significant noise source at higher frequencies $(500-3550 \mathrm{~Hz})$, levels were relatively low compared to those of man-made noise in the low-frequency band $(10-500 \mathrm{~Hz})$. These data demonstrated that seismic survey and shipping noise dominated the ambient noise environment and chronically elevated noise levels across the northern Gulf of Mexico ecosystem below $500 \mathrm{~Hz}$ throughout the multi-year study.

Several studies have previously examined patterns of ambient noise in the northern Gulf of Mexico (Newcomb et al. 2002, Snyder 2007, Snyder \& Orlin 2007); however, differences in sensor technology, noise analysis methods, and exact locations used for acoustic recordings between these studies and ours preclude direct comparisons of the data. Differences in averaging time, for instance, can greatly influence the measured sound pressure levels. For example, median $L_{\text {eq }}(\mathrm{dB}$ re $1 \mu \mathrm{Pa}$ ) during the seismic survey at Site H-1 between 28 September 2011 and 25 January 2012 measured $114 \mathrm{~dB}$ using a $1 \mathrm{~h}$ integration time

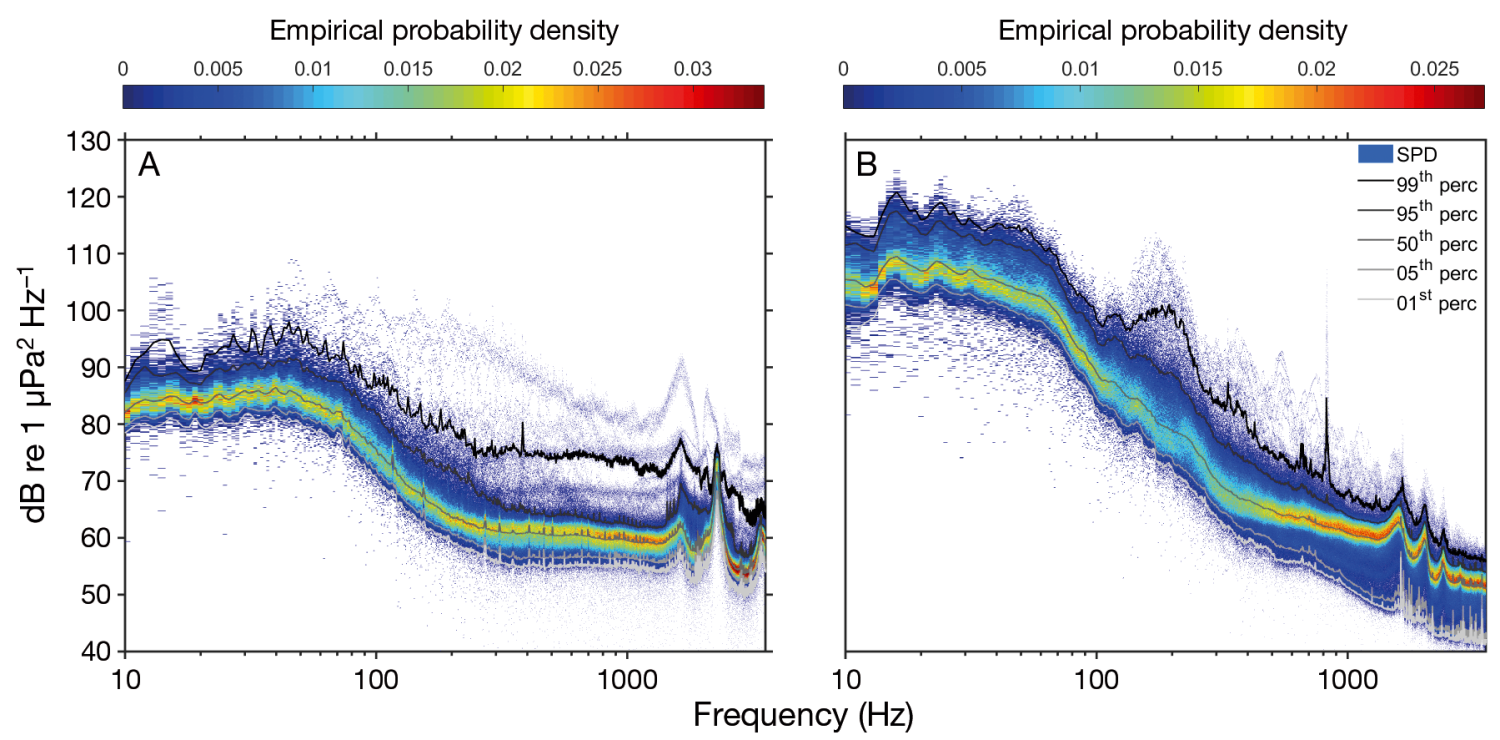

Fig. 8. Spectral probability density (SPD) plots illustrating the statistical distribution of sound pressure levels $\left(\mathrm{dB}\right.$ re $1 \mu \mathrm{Pa}^{2}$ $\mathrm{Hz}^{-1}$ ) averaged over $1 \mathrm{~s}$ time intervals, with a frequency resolution of $1 \mathrm{~Hz}$ for (A) $5 \mathrm{~d}$ with sperm whale foraging clicks at Site H-6 and (B) $5 \mathrm{~d}$ with seismic survey activity at Site H-1 
and $124 \mathrm{~dB}$ using a 1 min integration time. A general comparison of these different datasets across time, however, can inform long-term trends in the acoustic environment of the Gulf of Mexico. Those studies also have relatively limited geographical sampling, with acoustic data collected at 1 or 2 locations. Because the data reported by Snyder and Orlin (Snyder 2007, Snyder \& Orlin 2007) were collected with Naval Oceanographic acoustic sensors, the exact locations are not reported, but appear to be close to our H-6 location. These previous studies and our data all identify shipping activity and seismic surveys as major noise contributors to the Gulf of Mexico. However, our study found that sound levels from shipping activity were not nearly as pronounced as those from the seismic surveys, which, in many cases, persisted for months.

Seismic airgun noise dominated the northern Gulf of Mexico ambient noise environment between 2010 and 2012, producing the most pervasive and dispersed noise recorded during our study. During a typical seismic survey, each airgun fires sharp, broadband, low-frequency bursts of gas every 10 to $30 \mathrm{~s}$ towards the seabed (e.g. Greene \& Richardson 1988, Dragoset 1990, 2000, Caldwell \& Dragoset 2000). In many instances, we found that the time between seismic pulses was occupied by a series of multiple arrivals of the same reverberated pulse immediately following the original (Guerra et al. 2011, 2016), thus inundating the soundscape with near-continuous elevated noise levels. Our study also illustrates that seismic airgun noise in the northern Gulf of Mexico propagated over a large spatial scale of several hundred kilometers, exposing a wide range of species and habitats to chronically elevated noise levels. One notable seismic survey originated within the Mississippi Canyon, near H-3 where the sound from the airgun pulses propagated approximately $620 \mathrm{~km}$ to the Dry Tortugas (near H-7), and $165 \mathrm{~km}$ south-east to Site H-2, spanning at least $700 \mathrm{~km}$ across the Mississippi Fan.

In this study, we calculated the overall sound levels between 10 and $500 \mathrm{~Hz}$ that were received by the bottom-mounted hydrophones during time periods with seismic surveys. Those seismic pulses were recorded off-axis of the airgun signal in most, if not all instances. One would expect the sound pressure levels to increase with reduced distance to, and when directly below, an active airgun. Therefore, it should be recognized that the measurements presented in this study do not reflect the received level of airgun pulses for marine organisms positioned closer to the sound source, but illustrate the spatial and temporal extent of the seismic survey activity in the Gulf of Mexico basin.

To our knowledge, the spatial acoustic coverage of a single seismic survey has not been demonstrated in the Gulf of Mexico prior to this study. However, low-frequency sound propagating over 100s of kilometers is not exceptional (Nieukirk et al. 2004, Thode et al. 2010). In shallow-water environments, Greene \& Richardson (1988) recorded seismic airgun arrays as far as $73 \mathrm{~km}$ from the sound source, while in deepwater settings, like the Gulf of Mexico Basin, lowfrequency sound can propagate over far greater distances than in shallow-water environments (Hildebrand 2009).

In situ assessments of the effects of seismic surveys on marine organisms illustrate varying responses from airgun noise exposure. Seismic airgun surveys have been shown to severely influence fish distribution, abundance, and catch rates, indicating strong behavioral responses to exposure (Engås et al. 1996, Engås \& Løkkeborg 2002, Løkkeborg et al. 2012a,b). Controlled exposure experiments on fish elicited changes in swimming patterns and alarm responses (McCauley et al. 2000, Wardle et al. 2001, Fewtrell \& McCauley 2012), and caused extensive ear damage after exposure to seismic airgun pulses (McCauley et al. 2003), with no observed recovery $58 \mathrm{~d}$ postexposure. Sea turtles, which are threatened or endangered in the Gulf of Mexico, were observed to increase swimming activity and avoidance in response to seismic airgun exposure (DeRuiter \& Doukara 2012).

Invertebrates, such as cephalopods have been documented to experience significant trauma after exposure to intense low-frequency signals (Solé et al. 2013), as well as physiological and behavioral changes during exposure to seismic airguns (McCauley et al. 2000, Fewtrell \& McCauley 2012). Aguilar de Soto et al. (2013) reported malformations and delayed development of scallop larvae due to controlled exposure to seismic pulse playbacks. Such evidence of damage to soft-bodied organisms from high-intensity seismic airgun pulses presents concern for larger impacts on the Gulf of Mexico marine ecosystem at lower trophic levels.

Marine mammals, including sperm and humpback whales, have exhibited avoidance reactions to active airguns (Malme et al. 1984, Mate et al. 1994, Richardson et al. 1995, McCauley et al. 2000), and changes in vocal behavior and foraging efforts (Bowles et al. 1994, Jochens et al. 2008). Blue and fin whales have also been documented to drastically alter their vocal behavior and exhibit avoidance in response to seismic surveys (Di Iorio \& Clark 2010, Castellote et al. 
2012). Other studies, however, found no convincing evidence indicating that sperm whales avoid seismic survey activities (Wardle et al. 2001, Madsen et al. 2002, Jochens et al. 2008, Miller et al. 2009), though subtle behavior changes were observed (e.g. foraging rates). The question arises whether some individuals risk remaining in a heavily ensonified area in favor of food source availability, breeding opportunities, or territorial behavior.

Exposure to high-amplitude anthropogenic noise has been observed to lead to disorientation (Cox et al. 2006), as well as impaired predator and prey detection, and to compromise conspecific communication (Southall et al. 2000, Clark et al. 2009, Williams et al. 2014). Chronic noise exposure induced by seismic surveys may lead to changes in respiration (Richardson et al. 1995), reduction in food consumption, and poor health in some species. Additionally, long-term site abandonment of certain species could potentially affect those which prey on them.

Existing US regulatory measures classify sounds from seismic airgun surveys as impulsive, and the permissible exposure level to seismic airgun sound is established as if the sound were impulsive regardless of its actual acoustic characteristics. The resultant application of an acute sound exposure metric does not account for the chronic noise characteristics of reverberated and reflected seismic impulses after propagation over many 10s of kilometers or more (Guerra et al. 2011, 2016). Moreover, none of the currently implemented mitigation measures protect nonmammalian marine organisms, despite the evidence that supports the conclusion that noise exposure can both subtly and drastically affect their physiology or behavior (National Research Council 2003).

At present, available data are insufficient to accurately assess the long-term impacts of marine organisms exposed to chronically elevated noise levels (Parsons et al. 2009, Kight \& Swaddle 2011, Ellison et al. 2012, Hawkins et al. 2015, Shannon et al. 2015, de Soto 2016). In addition, the recognition of anthropogenic noise as a stressor for marine mammals (Southall et al. 2007, Hildebrand 2009, Ellison et al. 2012) and the concerns for synergistic cumulative impacts from multiple stressors on the Gulf of Mexico marine ecosystem warrant continued noise monitoring and impact assessments. Given that these data were recorded shortly after the Deepwater Horizon Oil Spill, the combination of dispersed oil and high anthropogenic noise levels may represent cumulative stressors, and have an increased impact on marine mammals. It is important to document baseline sound levels to compare against future possible changes and perturbations, which may be critical in evaluating the status of marine ecosystems in the Gulf of Mexico (McDonald et al. 2008).

The analysis of ambient noise patterns in the context of impact assessment provides a mechanism to quantitatively characterize critical components of ocean habitats and evaluate broad level changes in physical environmental processes, vocally active biological constituents of an acoustic environment, and the contribution of anthropogenic sounds to ambient noise. Temporal and spatial variability are principle characteristics of ambient noise; thus, long-term studies are needed to statistically characterize the variability (Wenz 1972). The Gulf of Mexico is one of the most active shipping fairways and off-shore geophysical survey sites in the world, and anthropogenic activities will continue to increase. Understanding how chronic and increasing ambient noise could threaten this biologically important and diverse ecosystem is paramount to making informed future management decisions.

Acknowledgements. We thank D. Doxey, C. TessagliaHymes, and D. Salisbury for assistance with deployment, recovery, and synchronization and H. Klinck and P. Marchetto for MARU characterization. H. Klinck provided helpful feedback on the text. Funding for data collection was provided through a contract from BP Production and Exploration, Inc., with scientific input from the National Oceanic and Atmospheric Administration's Southeast Fisheries Science Center and Office of Response and Restoration; BP had no role in the study design or execution and no influence over the reported results presented here. The statements, findings, and conclusions are those of the authors, and do not necessarily reflect the views of BP, or any State or Federal Natural Resource Trustee.

\section{LITERATURE CITED}

Aguilar de Soto N (2016) Peer-reviewed studies on the effects of anthropogenic noise on marine invertebrates: from scallop larvae to giant squid. Adv Exp Med Biol 875: $17-26$

Aguilar de Soto N, Delorme N, Atkins J, Howard S, Williams J, Johnson M (2013) Anthropogenic noise causes body malformations and delays development in marine larvae. Sci Rep 3:2831

Andrew RK, Howe BM, Mercer JA (2011) Long-time trends in ship traffic noise for four sites off the North American west coast. J Acoust Soc Am 129:642-651

ANSI (American National Standard Institute) (1994) American national standard acoustical terminology. Acoustical Society of America, New York, NY

Au WWL, Hastings MC (2008) Principles of marine bioacoustics. Springer, New York, NY

Backus RH, Schevill WE (1966) Physeter clicks. In: Norris KS (ed) Whales, dolphins and porpoises. University of California, Berkeley, CA, p 510-528 
Bioacoustics Research Program (2015) Raven Pro 1.5: interactive sound analysis software. Cornell Lab of Ornithology, Ithaca, NY. www.birds.cornell.edu/brp/raven/ RavenOverview.html

Bowles AE, Smultea M, Wursig B, DeMaster DP, Palka D (1994) Relative abundance and behavior of marine mammals exposed to transmission from the Heard Island feasibility test. J Acoust Soc Am 96:2469-2484

Caldwell J, Dragoset W (2000) A brief overview of seismic air-gun arrays. Leading Edge 19:898-902

Calupca TA, Fristrup KM, Clark CW (2000) A compact digital recording system for autonomous bioacoustic monitoring. J Acoust Soc Am 108:2582

Castellote M, Clark CW, Lammers MO (2012) Fin whale (Balaenoptera physalus) population identity in the western Mediterranean Sea. Mar Mamm Sci 28:325-344

Cato DH (1992) The biological contribution to the ambient noise in waters near Australia. Acoust Aust 20:76-80

Clark CW, Ellison WT, Southall BL, Hatch L, Van Parijs SM, Frankel A, Ponirakis D (2009) Acoustic masking in marine ecosystems: intuitions, analysis, and implication. Mar Ecol Prog Ser 395:201-222

> Clark CW, Rice AN, Ponirakis DW, Dugan PJ (2011) Marine acoustic ecologies and acoustic habitats: concepts, metrics, and realities. J Acoust Soc Am 130:2320

Cowan JP (1993) Handbook of environmental noise. Wiley, New York, NY

Cox TM, Ragen TJ, Read AJ, Vos E and others (2005) Understanding the impacts of anthropogenic sound on beaked whales. J Cetacean Res Manage 7:177-187

> Crain CM, Kroeker K, Halpern BS (2008) Interactive and cumulative effects of multiple human stressors in marine systems. Ecol Lett 11:1304-1315

Day JW, Arancibia AY, Mitsch WJ, Lara-Dominguez AL and others (2003) Using ecotechnology to address water quality and wetland habitat loss problems in the Mississippi basin: a hierarchical approach. Biotechnol Adv 22: 135-159

DeRuiter SL, Doukara KL (2012) Loggerhead turtles dive in response to airgun sound exposure. Endang Species Res 16:55-63

> Di Iorio L, Clark CW (2010) Exposure to seismic survey alters blue whale acoustic communication. Biol Lett 6: 51-54

Diaz JR, Solow A (1999) Ecological and economic consequences of hypoxia: Topic 2 report for the integrates assessment on hypoxia in the Gulf of Mexico. In: Book 16. NOAA Coastal Ocean Program, Silver Spring, MD, p 1-45

> Dragoset WH (1990) Air-gun array specs: a tutorial. Leading Edge 9:24-32

> Dragoset B (2000) Introduction to air guns and air-gun arrays. Leading Edge 19:892-897

Dugan PJ, Ponirakis DW, Zollweg JA, Pitzrick MS and others (2011) SEDNA - bioacoustic analysis toolbox. IEEE OCEANS 2011:1-10

Ellison WT, Southall BL, Clark CW, Frankel AS (2012) A new context-based approach to assess marine mammal behavioral responses to anthropogenic sounds. Conserv Biol 26:21-28

> Engås A, Løkkeborg S (2002) Effects of seismic shooting and vessel-generated noise on fish behaviour and catch rates. Bioacoustics 12:313-316

Engås A, Lokkeborg S, Ona E, Soldal AV (1996) Effects of seismic shooting on local abundance and catch rates of cod (Gadus morhua) and haddock (Melanogrammus aeglefinus). Can J Fish Aquat Sci 53:2238-2249

Fewtrell JL, McCauley RD (2012) Impact of air gun noise on the behaviour of marine fish and squid. Mar Pollut Bull 64:984-993

Goold JC, Jones SE (1995) Time and frequency domain characteristics of sperm whale clicks. J Acoust Soc Am 98:1279-1291

> Greene CR, Richardson WJ (1988) Characteristics of marine seismic survey sounds in the Beaufort Sea. J Acoust Soc Am 83:2246-2254

> Guerra M, Thode AM, Blackwell SB, Macrander AM (2011) Quantifying seismic survey reverberation off the Alaskan North Slope. J Acoust Soc Am 130:3046-3058

Guerra M, Dugan PJ, Ponirakis DW, Popescu M, Shiu Y, Rice AN, Clark CW (2016) High-resolution analysis of seismic air gun impulses and their reverberant field as contributors to an acoustic environment. In: Popper AN, Hawkins A (eds) The effects of noise on aquatic life II. Springer, New York, NY, p 371-379

Hawkins AD, Pembroke AE, Popper AN (2015) Information gaps in understanding the effects of noise on fishes and invertebrates. Rev Fish Biol Fish 25:39-64

Hildebrand JA (2009) Anthropogenic and natural sources of ambient noise in the ocean. Mar Ecol Prog Ser 395:5-20

Jochens A, Biggs D, Benoit-Bird K, Engelhaupt D and others (2008) Sperm whale seismic study in the Gulf of Mexico: synthesis report. OCS Study MMS 2008-006, Minerals Management Service, Gulf of Mexico OCS Region, US Department of the Interior, New Orleans, LA

Karnauskas M, Schirripa MJ, Kelble CR, Cook GS, Craig JK (2013) Ecosystem status report for the Gulf of Mexico. NOAA Tech Mem NMFS-SEFSC-653

Kight CR, Swaddle JP (2011) How and why environmental noise impacts animals: an integrative, mechanistic review. Ecol Lett 14:1052-1061

Løkkeborg S, Ona E, Vold A, Salthaug A (2012a) Effects of sounds from seismic air guns on fish behavior and catch rates. In: Popper AN, Hawkins A (eds) The effects of noise on aquatic life. Springer, New York, NY, p 415-419

> Løkkeborg S, Ona E, Vold A, Salthaug A (2012b) Sounds from seismic air guns: gear- and species-specific effects on catch rates and fish distribution. Can J Fish Aquat Sci 69:1278-1291

Love M, Baldera A, Yeung C, Robbins C (2013). The Gulf of Mexico ecosystem: a coastal and marine atlas. Ocean Conservancy, Gulf Restoration Center, New Orleans, LA

Madsen PT, Mohl B, Nielsen BK, Wahlberg M (2002) Male sperm whale behaviour during exposures to distant seismic survey pulses. Aquat Mamm 28:231-240

> Madsen PT, Wahlberg M, Tougaard J, Lucke K, Tyack P (2006) Wind turbine underwater noise and marine mammals: implications of current knowledge and data needs. Mar Ecol Prog Ser 309:279-295

Malme CI, Miles PI, Clark CW, Tyack P, Bird JE (1984) Investigations of the potential effects of underwater noise from petroleum industry activities on migrating gray whale behavior-Phase 2: January 1984. Bolt, Beranek and Newman, Cambridge, MA

> Mate BR, Stafford KM, Ljungbald DK (1994) A change in sperm whale (Physeter macrocephalus) distribution correlated to seismic surveys in the Gulf of Mexico. J Acoust Soc Am 96:3268

Maze-Foley K, Mullin KD (2006) Cetaceans of the oceanic northern Gulf of Mexico: distributions, group sizes and 
interspecific associations. J Cetacean Res Manag 8: 203-213

McCauley RD, Fewtrell JL, Duncan AJ, Jenner C and others (2000) Marine seismic surveys - a study of environmental implications. APPEA J 40:692-706

McCauley RD, Fewtrell J, Popper AN (2003) High intensity anthropogenic sound damages fish ears. J Acoust Soc Am 113:638-642

McDonald MA, Hildebrand JA, Wiggins SM, Ross D (2008) A 50 year comparison of ambient ocean noise near San Clemente Island: a bathymetrically complex coastal region off Southern California. J Acoust Soc Am 124: 1985-1992

Merchant ND, Barton TR, Thompson PM, Pirotta E, Dakin DT, Dorocicz J (2013) Spectral probability density as a tool for ambient noise analysis. J Acoust Soc Am 133: EL262

Merchant ND, Fristrup KM, Johnson MP, Tyack PL, Witt MJ, Blondel P, Parks SE (2015) Measuring acoustic habitats. Methods Ecol Evol 6:257-265

Miller PJO, Johnson MP, Madsen PT, Biassoni N, Quero M, Tyack PL (2009) Using at-sea experiments to study the effects of airguns on the foraging behavior of sperm whales in the Gulf of Mexico. Deep-Sea Res I 56: 1168-1181

Morrissey RP, Ward J, DiMarzio N, Jarvis S, Moretti DJ (2006) Passive acoustic detection and localization of sperm whales (Physeter macrocephalus) in the tongue of the ocean. Appl Acoust 67:1091-1105

National Research Council (2003) Ocean noise and marine mammals. National Academy Press, Washington, DC

Newcomb J, Fisher R, Field R, Rayborn G and others (2002) Measurements of ambient noise and sperm whale vocalizations in the northern Gulf of Mexico using near bottom hydrophones. IEEE OCEANS 02:1365-1371

Nieukirk SL, Stafford KM, Mellinger DK, Dziak RP, Fox CG (2004) Low-frequency whale and seismic airgun sounds recorded in the mid-Atlantic Ocean. J Acoust Soc Am 115:1832-1843

Nixon LD, Shepard NK, Bohannon CM, Montgomery TM, Kazanis EG, Gravois MP (2009) Deepwater Gulf of Mexico 2009: interim report of 2008 highlights. OCS Report MMS 2009-016. Minerals Management Service, Gulf of Mexico OCS Region, US Department of the Interior, New Orleans, LA

- Parsons ECM, Dolman SJ, Jasny M, Rose NA, Simmonds MP, Wright AJ (2009) A critique of the UK's JNCC seismic survey guidelines for minimising acoustic disturbance to marine mammals: best practise? Mar Pollut Bull 58:643-651

Peterson APG, Gross EE (1978) Handbook of noise measurement, $8^{\text {th }}$ edn. GenRad, Concord, MA

Rice AN, Palmer KJ, Muirhead CA, Tielens JT, Clark CW (2014) Potential Bryde's whale (Balaenoptera edeni) calls recorded in the northern Gulf of Mexico. J Acoust Soc Am 135:3066-3076

Richardson WJ, Greene CR, Malme CI, Thomson DH (1995) Marine mammals and noise, $1^{\text {st }}$ edn. Academic Press, San Diego, CA

Editorial responsibility: Brandon L. Southall, Santa Cruz, California, USA (Guest Editor)
Rolland RM, Parks SE, Hunt KE, Castellote M and others (2012) Evidence that ship noise increases stress in right whales. Proc R Soc B 279:2363-2368

Roth EH, Hildebrand JA, Wiggins SM, Ross D (2012) Underwater ambient noise on the Chukchi Sea continental slope from 2006-2009. J Acoust Soc Am 131:104-110

Samuel Y, Morreale SJ, Clark CW, Greene CH, Richmond ME (2005) Underwater, low-frequency noise in a coastal sea turtle habitat. J Acoust Soc Am 117:1465-1472

> Shannon G, McKenna MF, Angeloni LM, Crooks KR and others (2015) A synthesis of two decades of research documenting the effects of noise on wildlife. Biol Rev, doi: 10.1111/brv.12207

Sih A, Bell AM, Kerby JL (2004) Two stressors are far deadlier than one. Trends Ecol Evol 19:274-276

- Simard Y, Lepage R, Gervaise C (2010) Anthropogenic sound exposure of marine mammals from seaways: estimates for lower St. Lawrence Seaway, eastern Canada. Appl Acoust 71:1093-1098

> Slabbekoorn H, Bouton N, van Opzeeland I, Coers A, ten Cate C, Popper AN (2010) A noisy spring: the impact of globally rising underwater sound levels on fish. Trends Ecol Evol 25:419-427

Snyder MA (2007) Long-term ambient noise statistics in the Gulf of Mexico. PhD dissertation, University of New Orleans, New Orleans, LA

Snyder MA, Orlin PA (2007) Ambient noise classification in the Gulf of Mexico. IEEE OCEANS 2007:1-10

Solé M, Lenoir M, Durfort M, Lopez-Bejar M, Lombarte A, Andre M (2013) Ultrastructural damage of Loligo vulgaris and Illex coindetii statocysts after low frequency sound exposure. PLOS ONE 8:e78825

> Southall BL, Schusterman RJ, Kastak D (2000) Masking in three pinnipeds: underwater, low-frequency critical ratios. J Acoust Soc Am 108:1322-1326

Southall BL, Bowles AE, Ellison WT, Gentry JJF and others (2007) Marine mammal noise exposure criteria: initial scientific recommendations. Aquat Mamm 33:411-521

Thode A, Kim KH, Greene CR Jr, Roth E (2010) Long range transmission loss of broadband seismic pulses in the Arctic under ice-free conditions. J Acoust Soc Am 128:EL181

Urick RJ (1986) Ambient noise in the sea. Peninsula Publishing, Los Altos Hills, CA

Wahlberg M (2002) The acoustic behaviour of diving sperm whales observed with a hydrophone array. J Exp Mar Biol Ecol 281:53-62

Wardle CS, Carter TJ, Urquhart GG, Johnstone ADF, Ziolkowski AM, Hampson G, Mackie D (2001) Effects of seismic air guns on marine fish. Cont Shelf Res 21:1005-1027

Watkins WA (1980) Acoustics and the behavior of sperm whales. In: Busnel RG, Fish JF (eds) Animal sonar systems. Plenum Press, New York, NY

- Wenz GM (1962) Acoustic ambient noise in the ocean: spectra and sources. J Acoust Soc Am 34:1936-1956

- Wenz GM (1972) Review of underwater acoustics research: noise. J Acoust Soc Am 51:1010-1024

Williams R, Clark CW, Ponirakis D, Ashe E (2014) Acoustic quality of critical habitats for three threatened whale populations. Anim Conserv 17:174-185

Submitted: September 2, 2015; Accepted: May 26, 2016

Proofs received from author(s): July 22, 2016 